\title{
PAVIMENTOS RÍGIDOS: O FUTURO DAS ESTRADAS
}

\author{
BRASILEIRAS \\ RIGID PAVIMENTS: THE FUTURE OF BRAZILIAN \\ ROADS
}

\begin{abstract}
Augusto dos Santos Petzold
Universidade Presidente Antônio Carlos, Brasil E-mail: augustopetzold2014@gmail.com

Rickson Marinho Bernardi

Engenharia Civil

Universidade Presidente Antônio Carlos, Brasil E-mail: ricksonb05@gmail.com

Stefano Matteoni

Engenharia Civil

Universidade Presidente Antônio Carlos, Brasil E-mail: stmatteoni.engcivil@hotmail.com
\end{abstract}

Recebido: 20/05/2021 - Aceito: 20/05/2021

\section{Resumo}

Nas estradas brasileiras, movimentam-se diariamente grandes quantidades de veículos, e o peso infringido nas diferentes áreas construídas para este fim é enorme. Para resistir a essa quantidade voluptuosa de tensões precisa-se de um material não só resistente, mas também durável. Nos dias de hoje, por questões culturais, o tipo de pavimento mais utilizado é o pavimento flexível, que, em teoria, é menos custoso a curto prazo, de mais rápida construção e de reparo mais fácil. Através de dados coletados serão comparados os diferentes tipos de pavimento (rígido e flexível), evidenciando suas vantagens e desvantagens, buscando a conscientização e o entendimento de quais os métodos mais eficazes para satisfazer as necessidades das estradas brasileiras. As maiores variáveis se encontram na capacidade resistiva e na durabilidade do pavimento, porém, o fator econômico torna-se mais importante na maioria dos casos, onde busca-se satisfazer todas as necessidades através de um pavimento, que na maioria das vezes não é do tipo correto, com durabilidade 
Revista Multidisciplinar do Nordeste Mineiro, v.1, 2021/01

ISSN 2178-6925

mais baixa, de menor resistência, porém menos custosa, tendo assim um ilusório menor gasto de verbas, mas que a longo prazo pode acarretar em prejuízos. Em países como a Alemanha e os Estados Unidos, o pavimento rígido é o mais utilizado, 
principalmente em autoestradas, desde antes da Segunda Guerra Mundial, e no Brasil, ainda hoje, não é a mais utilizada.

Palavras-chave: Pavimentos Rígidos; Pavimentos Flexíveis; Estradas

\section{Abstract}

On Brazilian roads, large amounts of cars move daily, and the weight inflicted on the different areas built for this purpose is enormous. In order to resist this voluptuous amount of stresses, a material that is not only resistant but also durable is needed. Nowadays, for cultural reasons, the most used type of pavement is the flexible one, which, in theory, is less expensive in the short term, faster to build and easier to repair. Through the collected data, the different types of pavement (rigid and flexible) will be compared, showing it's advantages and disadvantages, seeking awareness and understanding of which methods are most effective to satisfy the needs of Brazilian roads. The biggest variables are found in the resistive capacity and durability of the pavement, however, the economic factor becomes more important in most cases, where it seeks to satisfy all needs through a pavement, which in most cases is not the same correct type, with lower durability, less resistance, but cheaper, those having an illusory lower expenditure of funds, but which in the long run can result in losses. In European countries, such as Germany and also in the United States of America, the rigid pavement is the most used, mainly on motorways, since before the World War II, and in Brazi, even today, it's not the most used.

\section{Keywords: Rigid floors; Flexible floors; Roads}

\section{Introdução}

Devido ao grande volume de veículos que percorrem o solo rodoviário brasileiro é preciso pensar qual o melhor método a ser utilizado nas rodovias a fim de suprir essa demanda. Segundo a Agência CNT Transporte Atual (2020) foram registrados 67.427 acidentes sendo destes, 55.756 com vítimas feridas ou mortas nas rodovias federais brasileiras, ainda que o número de acidentes esteja 2,6\% abaixo do registrado no ano de 2018 , o número de vítimas subiu $3,3 \%$ o que é algo 
Revista Multidisciplinar do Nordeste Mineiro, v.1, 2021/01

ISSN 2178-6925

preocupante, a título de curiosidade foram registrados 41.635 assassinatos no Brasil em 2019 , aproximadamente $26 \%$ a menos do número de acidentes com vítimas fatais. 
Segundo CNA (2012), somente $13,4 \%$ da malha rodoviária brasileira é considerada ótima; enquanto $29 \%$ foram consideradas boas; $31,5 \%$ consideradas regulares; 17,4\% aparecem como ruins e 9,5\% estão em péssimas condições.

Uma breve comparação entre o pavimento rígido e o flexível é a economia de combustível que os veículos que trafegam sobre o rígido infere sobre os que trafegam sobre o flexível em até $20 \%$, evidenciando assim um benefício financeiro no uso do pavimento rígido (Carvalho, 2019).

Quando comparados, o pavimento rígido apresenta uma tonalidade mais clara em virtude do cimento, material utilizado no preparo do concreto, proporcionando assim maior visibilidade ao motorista à noite, refletindo melhor a iluminação pública e diminuindo o calor pela incidência dos raios solares (Jaramillo, 2020).

Esse estudo tem como objetivo apresentar as principais diferenças entre pavimentos rígidos e flexíveis bem como expor a preferência de uso do pavimento rígido nas malhas rodoviárias brasileiras, sendo estas, tanto municipais, estaduais ou federais visando trazer mais segurança às usuários das rodovias e a diminuir o custo de concessionárias/governo com o reparo.

A grande questão a ser respondida é: se o pavimento rígido oferece um menor valor de manutenção, resistência maior, durabilidade maior e hoje em dia praticamente o mesmo preço de aplicação a curto prazo, porque ainda este não foi aplicado à malha rodoviária do nosso país?

A proposta desse estudo é conscientizar e informar a população de que é necessário que sejam feitas mudanças na estrutura rodoviária do país, somente através dessa informação que pode-se cobrar dos políticos o posicionamento correto diante dessa situação que o país enfrenta, de forma que se o a população não tem acesso à esse tipo de informação possivelmente continuaremos com um grande número de acidentes conforme explicado no início deste artigo, como também um custo absurdo de manutenção em "operações tapa-buraco".

\subsection{Objetivos}

\subsubsection{Objetivo Geral}


Revista Multidisciplinar do Nordeste Mineiro, v.1, 2021/01

ISSN 2178-6925

Conscientizar a população de que é possível ter estradas seguras e de alto padrão de qualidade no país, para que através desse conhecimento, os mesmos possam lutar por melhores condições das rodovias, entendendo que o futuro das estradas do Brasil seja a pavimentação rígida. 


\subsubsection{Objetivo Específico}

- Exemplificar sucintamente como é a distribuição de cargas no pavimento rígido e flexível;

- Demonstrar a diferença de durabilidade entre os dois;

- Conscientizar e informar a população dos problemas e apontar soluções;

- Demonstrar com exemplos que é possível disseminar o pavimento rígido no Brasil.

\section{Revisão da Literatura}

\subsection{Pavimento Rígido}

De acordo com José et al (2014), o pavimento rígido começou a ser difundido inicialmente na Europa, em especial na Alemanha na época da segunda guerra, onde já podiam contar com $92 \%$ de suas autoestradas em concreto.

\footnotetext{
"O pavimento rígido pode ser definido como aquele que apresenta uma camada de revestimento com uma rigidez superior às camadas inferiores, absorvendo praticamente todas as tensões provenientes das tensões $\mathrm{e}$ deformações da placa. O modelo de pavimentação rígida baseia-se na implementação de cimento como aglomerante hidráulico para interligação dos agregados envolvidos no concreto. Sendo a placa de cimento seu principal componente estrutural" (Araújo, 2016).
}

Segundo Flávia et al (2008), os pavimentos rígidos são aqueles nos quais a camada de revestimento tem uma rigidez ampla em relação às camadas inferiores, tornando a resistência a tensões maior. Esse tipo de pavimento tem vários métodos construtivos, pois, pode ser feito através do uso de placas de concreto de Cimento Portland simples, como também, por estruturas pré-moldadas.

\subsection{Pavimento Flexível}


Revista Multidisciplinar do Nordeste Mineiro, v.1, 2021/01

ISSN 2178-6925

De acordo com CNT (2016), o pavimento flexível é o mais utilizado nas estradas brasileiras, cerca de 99\%. Segundo o DNIT (2017), para implantação de pavimento flexível em pista simples com faixa de 3,6 metros e acostamento de 2,5 metros com revestimento em CAUQ com $10 \mathrm{~cm}$ de espessura para pista e 
Revista Multidisciplinar do Nordeste Mineiro, v.1, 2021/01

ISSN 2178-6925

acostamento, é necessário o custo médio de $\mathrm{R} \$ 3.159 .000,00$ por quilômetro, já para o pavimento rígido, é exigido o custo médio de $\mathrm{R} \$ 5.430 .000,00$ por quilômetro.

O pavimento flexível se caracteriza por não romper e é constituído principalmente de materiais betuminosos. Sua base pode ser composta por diversas camadas, como subleito, sub-base, base e revestimento. Seus esforços são distribuídos verticalmente, esse tipo de pavimento vem sendo aplicado de maneira acentuada nas últimas décadas, associado a esse volume os serviços de recapeamento, que se constituem em obras semelhantes às obras de pavimentação (Araújo, 2016).

Este sistema de pavimentação é menos custoso que o rígido sendo este um dos principais motivos pela sua escolha, deixando de lado a concepção de que sua preferência é somente devido a questões culturais ou técnicas.

\subsection{Execução do pavimento rígido}

O pavimento rígido é composto de placas de concreto de Cimento Portland (PCS) que podem durar até 30 anos (Fernandes, 2019).

As placas que compõem o pavimento rígido, seguem o modelo de fabricação da Associação Brasileira de Cimento Portland (ABCP, 2010).

Conforme DNIT (2005), prevê-se que o concreto aplicado deverá apresentar resistência característica à tração na flexão definida em projeto, geralmente estando na ordem de 4,5 MPa ou em pavimentos estruturalmente armados, resistência característica à compressão axial, em torno de $30 \mathrm{MPa}$.

De acordo com DNIT (2005), para que o mesmo tenha um bom desempenho o concreto das placas deve apresentar baixa variação volumétrica, evitando assim, trincas no pavimento, e posterior desgaste acelerado do pavimento.

O concreto do pavimento deve apresentar também uma baixa variação volumétrica; trabalhabilidade compatível ao equipamento a ser utilizado no espalhamento; adensamento e acabamento a fim de assegurar a durabilidade; e um consumo de cimento igual ou acima de $320 \mathrm{~kg} / \mathrm{m}^{3}$ de concreto (Fernandes, 2020). 
Revista Multidisciplinar do Nordeste Mineiro, v.1, 2021/01

ISSN 2178-6925

Em comparação ao pavimento rígido, o pavimento flexível tem a vantagem de ser mais barato conforme explicado acima, porém, tende a ser menos resistente e menos duradouro, possuindo um tempo de vida útil de apenas 10 anos (Fernandes, 2019). 


\subsection{Distribuição de esforços entre Pavimento Rígido e Flexível}

Com relação aos esforços que ambos os pavimentos receberão, tanto diariamente, quanto ao longo da sua vida útil, no pavimento flexível a carga se distribui em parcelas proporcionais à rigidez das camadas, todas as camadas sofrem deformações elásticas significativas, as deformações até um limite não levam ao rompimento, devendo ser considerada a qualidade do solo pois este é submetido a altas tensões e absorve maiores deflexões, em contrapartida no pavimento rígido a placa absorve maior parte das tensões, essa distribuição de cargas faz-se sobre uma área relativamente maior e a qualidade do solo pouco infere no comportamento estrutural pouco deformável sendo mais resistente à tração (Araújo, 2016).

Dessa forma explica-se a imensa diferença entre ambos pavimentos quando o assunto é durabilidade.

Figura 01: Representação das Cargas nos Pavimentos
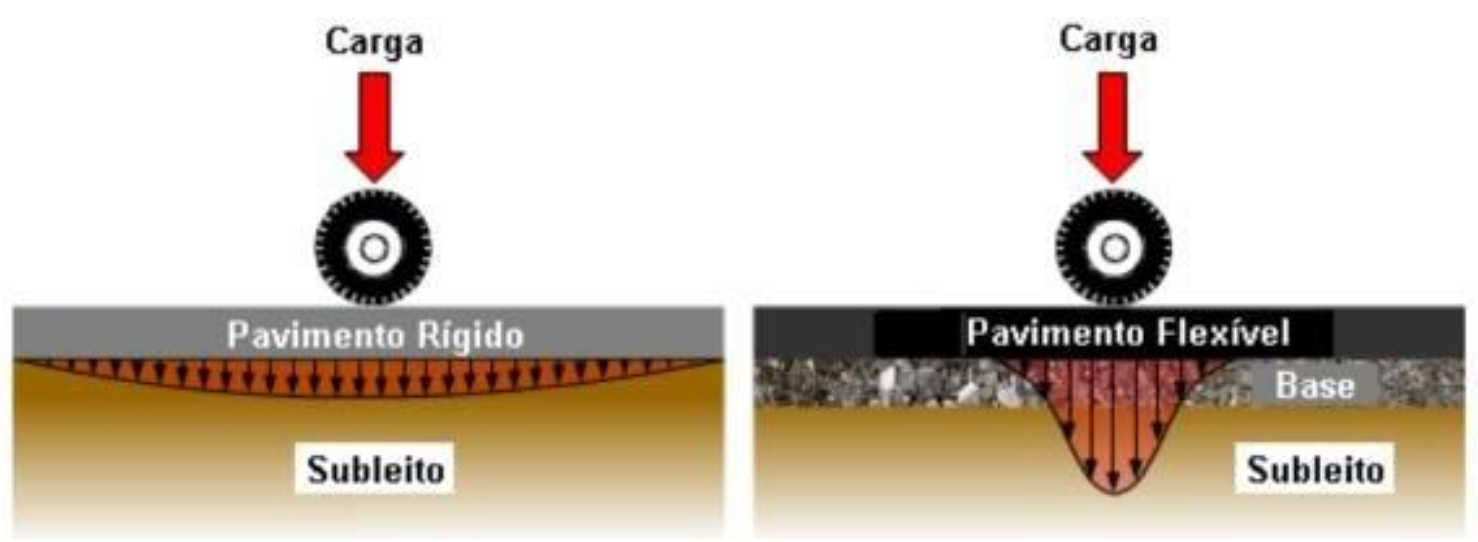

Fonte: Araújo, 2016.

\subsection{Principais Diferenças entre Pavimentos Rígidos e Pavimentos Flexíveis}

De acordo com Marques (2006) o pavimento flexível é constituído de revestimento betuminoso delgado sobre camadas puramente granulares, já o pavimento rígido por sua vez é constituído por placas de concreto de Cimento 
Revista Multidisciplinar do Nordeste Mineiro, v.1, 2021/01

ISSN 2178-6925

\section{Portland (PCS).}

Segundo DNIT (2017) um ponto de destaque nesta comparação é a questão econômica, onde, enquanto o pavimento flexível de início parece ser menos custoso, o rígido se sobressai no longo prazo devido à diminuição da necessidade de reparo da via. Isso acontece devido ao pavimento rígido ter uma vida útil 
Revista Multidisciplinar do Nordeste Mineiro, v.1,

$$
2021 / 01
$$

ISSN 2178-6925

substancialmente superior à do pavimento flexível precisando assim, de menos manutenções ao longo da sua vida útil (DNIT, 2017). Conforme Votorantim Cimentos (2017), as vantagens do pavimento rígidos sobre os pavimentos flexíveis também são ecológicas, pois, o uso do concreto é menos tóxico para o ser humano, e reduz os usos de recursos naturais.

Figura 02: Vantagens do uso do concreto

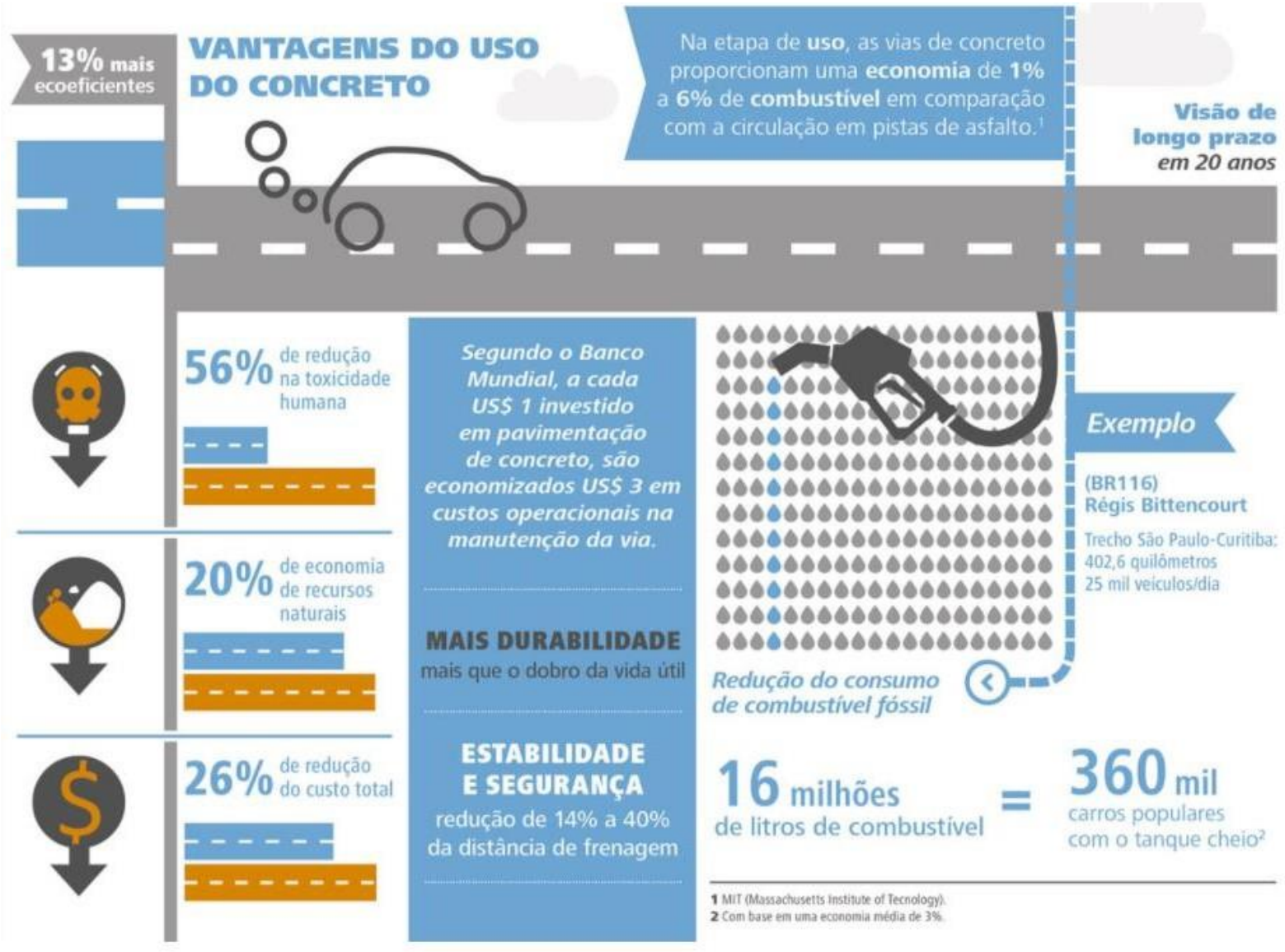

Fonte: Votorantim Cimentos, 2017.

\subsection{Benefícios técnicos do Pavimento Rígido}

Enquanto o pavimento flexível distribui as cargas que infere sobre ele, transmitindo-as para todas as suas camadas, no pavimento rígido, a placa de concreto as absorve devido a sua rigidez (Araújo, 2016).

Segundo DNIT (2006), no caso do pavimento flexível, faz-se necessário a execução de mais camadas para conseguir absorver o esforço que é inferido sobre 
Revista Multidisciplinar do Nordeste Mineiro, v.1, 2021/01

ISSN 2178-6925

o mesmo, sendo estas, conhecidas como: base, sub-base, reforço do subleito.

Como observado, o pavimento rígido dura aproximadamente 3 (três) vezes mais que o pavimento flexível (Fernandes, 2019). Abordando agora o que faz deste tipo de pavimento mais resistente, pode ser citado a propriedade das placas de concreto de Cimento Portland em absorver os esforços de flexão inferidos sobre o pavimento quando trafegam sobre o mesmo veículos pesados como ônibus ou 
caminhões, segundo ANPET (2018), no $32^{\circ}$ Congresso de Pesquisa e Ensino em Transporte realizado pela Associação Nacional de Pesquisa e Ensino em Transporte, foi substituído o pavimento flexível pelas placas de concreto de Cimento Portland na área de embarque/desembarque dos corredores de ônibus em Gramado justamente devido a ação de aceleração e desaceleração dos mesmos, para melhor trabalhar as grandes solicitações geradas por essas forças. Foi pensada a troca entre os dois tipos de pavimentos, a fim de evitar a aparição de patologias no pavimento flexível como corrugações, formação de trilha de rodas, solevamento da camada asfáltica entre outros, o que acaba por gerar transtornos e tem o poder de danificar os próprios ônibus que trafegam sobre a via (ANPET, 2018).

\subsection{Pavimento Rígido x Flexível: um século de "atraso"?}

O grande debate a ser promovido é voltado para essas ideias imediatistas de muitas lideranças governamentais no Brasil, sendo importante avaliar não somente o custo da execução da obra, mas considerar todos os custos diretos e indiretos que um pavimento pode trazer, como custo de manutenção da via e dos veículos que por ela trafegam. De acordo com Senço (1997), a Alemanha já possuía desde a década de 1940, 92\% de estradas em pavimento rígido, segundo a ABCP (2019), o Brasil possui somente $6.800 \mathrm{~km}$ de estradas com pavimento rígido e $99 \%$ de estradas com pavimento flexível.

Segundo Feldman (2020), morrem anualmente, cerca de 17 brasileiros no trânsito por 100 mil habitantes, enquanto na Alemanha, essa mesma taxa é de 4 por 100 mil.

De acordo com Arteris (2020), a rodovia Fernão Dias que liga São Paulo a Belo Horizonte é duplicada, uma estrada que conta com uma ótima infraestrutura mas ainda possui em sua maioria pavimento flexível. A importância de ter acesso a informações como essas está em conscientizar cada cidadão brasileiro de que é possível sim ter estradas boas no país como a Fernão Dias, ainda que esta contenha em sua maioria pavimento flexível.

A solução para tal problema está em cada brasileiro se posicionar como cidadão cobrando das autoridades novas atitudes acerca das vias que são 
Revista Multidisciplinar do Nordeste Mineiro, v.1, 2021/01

ISSN 2178-6925

responsáveis por conduzir alimentos, combustível, medicamentos (sendo estas responsáveis por abastecer desde grandes cidades a pequenos municípios) e também famílias. Segundo Arteris (2020), o tráfego na Fernão Dias conta com $34,8 \%$ por veículos comerciais e $65,2 \%$ por veículos de passeio, recebendo cerca de 250 mil veículos/dia e atendendo aproximadamente 16,6 milhões de habitantes 
Revista Multidisciplinar do Nordeste Mineiro, v.1,

\section{1/01}

ISSN 2178-6925

(pesquisa feita no trecho entre Contagem/MG e Guarulhos/SP).

Figura 03: Rodovia Fernão Dias

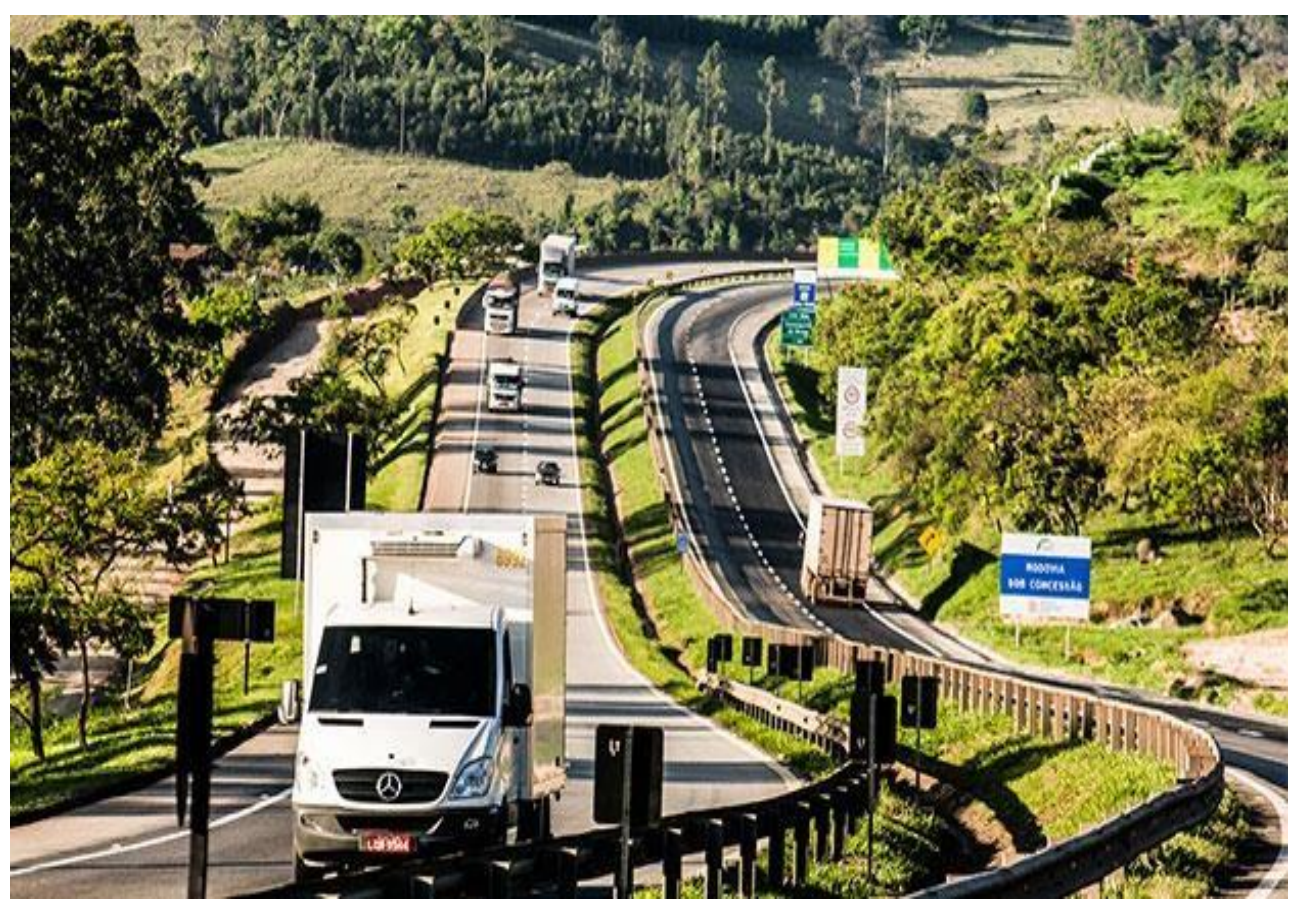

Fonte: Arteris, 2020.

\subsection{Cultura sobrepondo Desenvolvimento}

Segundo Bezerra (2018), desde a década de 50 com o governo de Juscelino Kubitscheck e seu plano 50 anos em 5 anos o Brasil passou a explorar bastante o setor rodoviário, com a chegada de grandes montadoras de carros como a Ford e Chrysler no país e também em virtude do petróleo barato à época, sendo construídos 20 mil quilômetros de estradas de rodagem nesse período. A título de estatística, a produção de petróleo em 1955 era de 2 (dois) milhões de barris, já em 1960 a produção passou para 30 (trinta) milhões de barris, um crescimento de $1500 \%$ em um período de 5 anos, tendo o produto interno bruto do Brasil crescido em média 7\% ao ano (Bezerra, 2018). O presidente "JK" faleceu no ano de 1976 em virtude de um acidente automobilístico quando viajava de São Paulo para o Rio de Janeiro (Bezerra, 2018).

A cultura implementada desde a década de 50 gera resultados até hoje, em 
Revista Multidisciplinar do Nordeste Mineiro, v.1, 2021/01

ISSN 2178-6925

resposta a essa afirmação o número de novos emplacamentos tem crescido bastante nos últimos anos. Segundo Autoo (2020), no ano de 2017 foram realizados 2.170.263 milhões de novos emplacamentos, no ano de 2018 foram realizados 2.468.068 milhões de novos emplacamentos e no ano de 2019 foram realizados 2.657.695 milhões de novos emplacamentos. 
Revista Multidisciplinar do Nordeste Mineiro, v.1, $2021 / 01$

ISSN 2178-6925

Figura 04: Total de emplacamentos de veículos leves anual

Total de emplacamentos de veículos leves no Brasil por mês e ano

\begin{tabular}{lll} 
Ano & Jan & Total \\
\hline 2020 & 183.945 & 1.501 .697 \\
2019 & 190.613 & 2.657 .695 \\
2018 & 175.448 & 2.468 .068 \\
2017 & 143.439 & 2.170 .263
\end{tabular}

Mais 9 linhas

www.autoo.com.br > emplacamentos

Emplacamentos de veículos e marcas no Brasil - AUTOO

Fonte: Autoo, 2020.

A resposta é que a cultura implementada desde 1956 com o governo "JK" tem mais voz que os vários bons exemplos que o Brasil tem para se embasar ao redor do mundo. Realmente o lema do finado presidente "50 anos em 5 anos" gerou no curto prazo um desenvolvimento econômico absurdo para época, observando o grande crescimento do petróleo (Bezerra, 2018). Entretanto o Brasil também está há 60 anos "estagnado" no mesmo plano de governo quando o assunto são rodovias.

Em diversos países, principalmente Alemanha e Estados Unidos, o pavimento de concreto passou a ter preferência para auto-estradas, antes da Segunda Guerra Mundial. Nessa época a Alemanha tinha cerca de $92 \%$ de suas auto-estradas em concreto. No fim de 1950 os Estados Unidos tinham em torno de $89 \%$ das grandes vias urbanas e $79 \%$ das vias rurais pavimentadas com concreto (Marinho \& Vieira, 2014)

Mediante a análise de todo o conteúdo apresentado, percebe-se claramente que a questão cultural no Brasil pesa mais do que a vontade de mudar de patamar no cenário econômico mundial no quesito infraestrutura, não é por falta de experiência no "ramo" rodoviário. 
Revista Multidisciplinar do Nordeste Mineiro, v.1, 2021/01

ISSN 2178-6925

\section{Considerações Finais}

No Brasil, o avanço na construção civil se faz mais lenta que nos países do primeiro mundo, e isto é evidente quando olhamos para as estradas do país. Ainda de acordo com ABCP (2019), o Brasil possui 99\% de suas estradas compostas por pavimento flexível. 
Visando a crescente alta do número de emplacamentos nos últimos anos, pode-se concluir que, os cidadãos brasileiros, tem optado por veículos automotores como meio de transporte (Autoo, 2020). De acordo com AND (2017), o número de carros não para de crescer no país, sendo um automóvel para cada 4,4 habitantes e à época da pesquisa eram 45,4 milhões de veículos desse tipo. Segundo Agência Brasil (2018) no país foram contabilizadas 26,4 milhões de motos, uma proporção de uma moto para cada 7,86 habitantes. Segundo Nubank (2020) a taxa Selic no ano vigente a pesquisa é de $2 \%$ e conforme Dino (2020) os financiamentos automotivos contam com taxas mais baixas quando a Taxa Selic diminui, por causa disso, comprar um carro financiado fica mais barato em cenários como esse.

O pavimento rígido tem inúmeras vantagens quanto ao pavimento flexível, tanto que segundo Fernandes (2019), o pavimento rígido tem uma durabilidade de até 3 (três) vezes maior que o do pavimento flexível, que, por sua vez, é menos oneroso, todavia tem uma durabilidade aproximada de 10 (dez) anos.

De acordo com Votorantim Cimentos (2017), o pavimento rígido é o mais indicado quando comparado ao pavimento flexível, desde a questão econômica até a questão de segurança, onde, segundo Feldman (2020), morrem anualmente cerca de 17 pessoas no trânsito brasileiro por 100 mil habitantes, enquanto na Alemanha, onde há predominância de pavimentos rígidos, a taxa é de 4 pessoas por 100 mil habitantes.

Busca-se o emprego deste método com mais constância nas estradas brasileiras para assim diminuir os desgastes causados pelos veículos e de certa forma diminuir os gastos a longo prazo, sem comprometer o curto prazo. A cultura de pavimentos feitos de petróleo (asfalto) estabelecida por "JK" em 1955 não pode prevalecer nos tempos atuais, é necessário que seja pensado melhorias para servir o povo brasileiro e suas atuais necessidades (Bezerra, 2018).

É preciso uma mudança nos métodos convencionais brasileiros acerca destas questões que envolvem a construção das estradas, pois assim o Brasil poderá ser comparado com países de $1^{\circ}$ mundo como a Alemanha, que na década de $40 \mathrm{com}$ a $2^{\underline{a}}$ Guerra Mundial foi totalmente destruída, e hoje, 80 anos depois, possui uma das infraestruturas mais sólidas do mundo (Bezerra, 2018).

O que deve ser cobrado dos novos políticos é uma posição diferente com relação à provisão de conforto e segurança para os próprios brasileiros, em vista que 
Revista Multidisciplinar do Nordeste Mineiro, v.1, 2021/01

ISSN 2178-6925

as rodovias é o meio de locomoção mais utilizado pelos cidadãos e estas são também responsáveis por transportar suprimentos. É necessário que cada brasileiro se posicione e garanta seus direitos pois, todo o cenário econômico indica para uma forte alta na compra de veículos automotores, e é necessário que além de juros atrativos, exista uma infraestrutura atrativa para os veículos transitarem (Dino, 2020). 
Revista Multidisciplinar do Nordeste Mineiro, v.1, $2021 / 01$

ISSN 2178-6925

\section{Referências}

MARINHO, J. E. ; CARNEIRO, L. A. V. Pavimentos de concreto: Histórico, Tipos e Modelos de Fadiga. Seção de Engenharia de Fortificação e Construção, Instituto Militar de Engenharia. Rio de Janeiro - RJ, 2014.

BIANCA, F. R. ; BRITA, I. R.; CASTRO, V. A. B. Estudo Comparativo Entre Pavimento Rígido e Flexível. Associação de Ensino Superior Unificado do Centro Leste. 2008

VIZZONI, R. ; Pavimento de Concreto: Solução Sustentável e Custo

Competitivo. Associação Brasileira de Cimento Portland - ABCP. 2009.

\section{SILVA, A. L. ; Estudo Comparativo Entre Pavimento Rígido e Pavimento}

Flexível. Centro Universitário de Maringá - UNICESUMAR. Maringá - PR, 2019.

Emplacamento de Veículos e Marcas no Brasil. Autoo, 2020. Disponível em: https://www.autoo.com.br/emplacamentos/. Acesso em: 18 out. 2020

FELDMAN, B. Alemanha x Brasil: $7 \times 1$ no futebol, $10 \times 1$ nas mortes de trânsito. Estadão, 2020. Disponível em: https://jornaldocarro.estadao.com.br/blog-doboris/alemanha-brasil-mortes-transito-estradas/\#: :text= Morrem\%20anualmente\% 2017\%20brasileiros\%20no,vezes\%20menor\%20que\%20no\%20Brasil. Acesso em: 22 out. 2020

BEZERRA, J. Juscelino Kubitschek. Toda Matéria, 2018. Disponível em: https://www.todamateria.com.br/juscelino-kubitschek/. Acesso em: 18 out. 2020

ARTERIS. Sobre a Concessão. 2020. Disponível em:

https://www.arteris.com.br/rodovias/fernao-dias/. Acesso em: 10 out. 2020 
Revista Multidisciplinar do Nordeste Mineiro, v.1, 2021/01

ISSN 2178-6925

Pavimento Rígido (concreto) x Flexível (asfalto). Revista Científica Multidisciplinar Núcleo do conhecimento. 2016.

CARVALHO, M. A. F. Estudo Comparativo entre Pavimento Flexível e Rígido 
Revista Multidisciplinar do Nordeste Mineiro, v.1, $2021 / 01$

ISSN 2178-6925

com Base nos Fatores Ecológicos, Econômicos e de Conservação. Centro Universitário de Maringá - UNICESUMAR. Maringá - PR, 2018

Avaliação de Ecoeficiência. Votorantim Cimentos, 2017. Disponível em:

https://www.votorantimcimentos.com.br/estudos casos/avaliacao-de-ecoeficienciapavimento-de-concreto-x-pavimento-de-asfalto/. Acesso em: 01 nov. 2020

Número total de acidentes em rodovias federais cai em 2019, mas números de mortos e feridos aumenta. CNT, 2020. Disponível em:

https://www.cnt.org.br/agencia-cnt/acidentes-rodovias-cai-2019-numero-mortosferidos-aumenta Acesso em: 18 out. 2020

Rodovias Sucateada. Progresso, 2012. Disponível em:

https://www.progresso.com.br/noticias/rodovias-sucateadas/78778/ . Acesso em: 5 out. 2020.

FILHO, J. M. M. ; ROCHA, E. G. A. Estudo comparativo entre pavimento flexível e rígido na pavimentação rodoviária. Revista Científica Multidisciplinar Núcleo do Conhecimento. 2018.

FERNANDES, A. Pavimento Rígido x Pavimento Flexível. Mapa da Obra, 2019.

Disponível em: https://www.mapadaobra.com.br/capacitacao/pavimento-rigidoflexivel/\#: :text=O\%20pavimento\%20r\%C3\%ADgido\%20\%C3\%A9\%20um,dura\%2 C\%20aproximadamente\%2C\%2010\%20anos. Acesso em: 28 set. 2020.

Associação Brasileira de Cimento Portland - ABCP. Manual de Placas de Concreto: Passeio Público. São Paulo, 2010.

Departamento Internacional de Infra-Estrutura de Transportes - DNIT. Manual de Pavimentos Rígidos. Rio de Janeiro, 2005. 
Revista Multidisciplinar do Nordeste Mineiro, v.1, 2021/01 ISSN 2178-6925

Faculdade Federal de Juiz de Fora - UFJF. Juiz de Fora - MG, 2006.

O que é a taxa Selic e como ela afeta seu dinheiro? Nubank, 2020. Disponível em: https://blog.nubank.com.br/taxa-selic/ Acesso em: 12 nov. 2020 
Revista Multidisciplinar do Nordeste Mineiro, v.1, $2021 / 01$

ISSN 2178-6925

Número de motos é maior que o de carros em 45\% das cidades. Agência Brasil, 2020. Disponível em:

https://agenciabrasil.ebc.com.br/geral/noticia/2018-07/numero-de-motos-e-maiorque-0-de-carros-em-45-das-

cidades\#: : :text=Em\%20todo\%200\%20pa\%C3\%ADs\%2C\%20foram,moto\%20para \%207\%2C86\%20habitantes Acesso em: 13 nov. 2020.

Brasil já tem um carro a cada 4 habitantes, diz Denatran. AND, 2020. Disponível em:

http://www.and.org.br/brasil-ja-tem-1-carro-a-cada-4-habitantes-dizdenatran/\#: : :text=0\%20n\%C3\%BAmero\%20de\%20 carros\%20n\%C3\%A3o, milh\%C 3\%B5es\%20de\%20ve\%C3\%ADculos\%20do\%20tipo Acesso em 10 nov. 2020.

Selic em baixa facilita o financiamento automotivo. Terra, 2020. Disponível em: https://www.terra.com.br/noticias/dino/selic-em-baixa-facilita-o-financiamentoautomotivo,fe6c10c93edaa1f1a7058ae866fece98kmmbbc1w.html\#: :text=\%22No\% 20geral\%2C\%20os\%20financiamentos\%20automotivos,momento\%22\%2C\%20afir ma\%200\%20especialista Acesso em 13 nov. 2020.

DA SILVA BARBOSA, Uende et al. reutilização do concreto como contribuição para a sustentabilidade na construção civil. Revista Multidisciplinar do Nordeste MineiroUnipac ISSN, v. 2178, p. 6925, 2018.

GOMES, Jarbas Herinson Dias et al. Análise Comparativa do sistema construtivo de alvenaria convencional e sistema construtivo de alvenaria estrutural em uma casa térrea em Teófilo Otoni. Revista Multidisciplinar do Nordeste Mineiro-Unipac ISSN, v. 2178, p. 6925, 2018.

SIQUEIRA, Rodrigo Alves et al. Análise Comparativa Entre O Concreto Usinado E O Concreto Produzido No Canteiro De Obra. Revista Multidisciplinar do Nordeste Mineiro-Unipac ISSN, v. 2178, p. 6925, 2018.

DA SILVA, Felipe Alves et al. ANÁLISE ERGONÔMICA NA CONSTRUÇÃO CIVIL: uma revisão de literatura. Revista Multidisciplinar do Nordeste Mineiro, v. 1, p. 1, 2019 
Revista Multidisciplinar do Nordeste Mineiro, v.1, 2021/01

ISSN 2178-6925

\section{FICHA DE ACOMPANHAMENTO}

Faculdade Presidente Antônio Carlos de Teófilo Oton

FICHA DE ACOMPANHAMENTO INDIVIDUAL DE ORIENTAÇĀO DE TCC

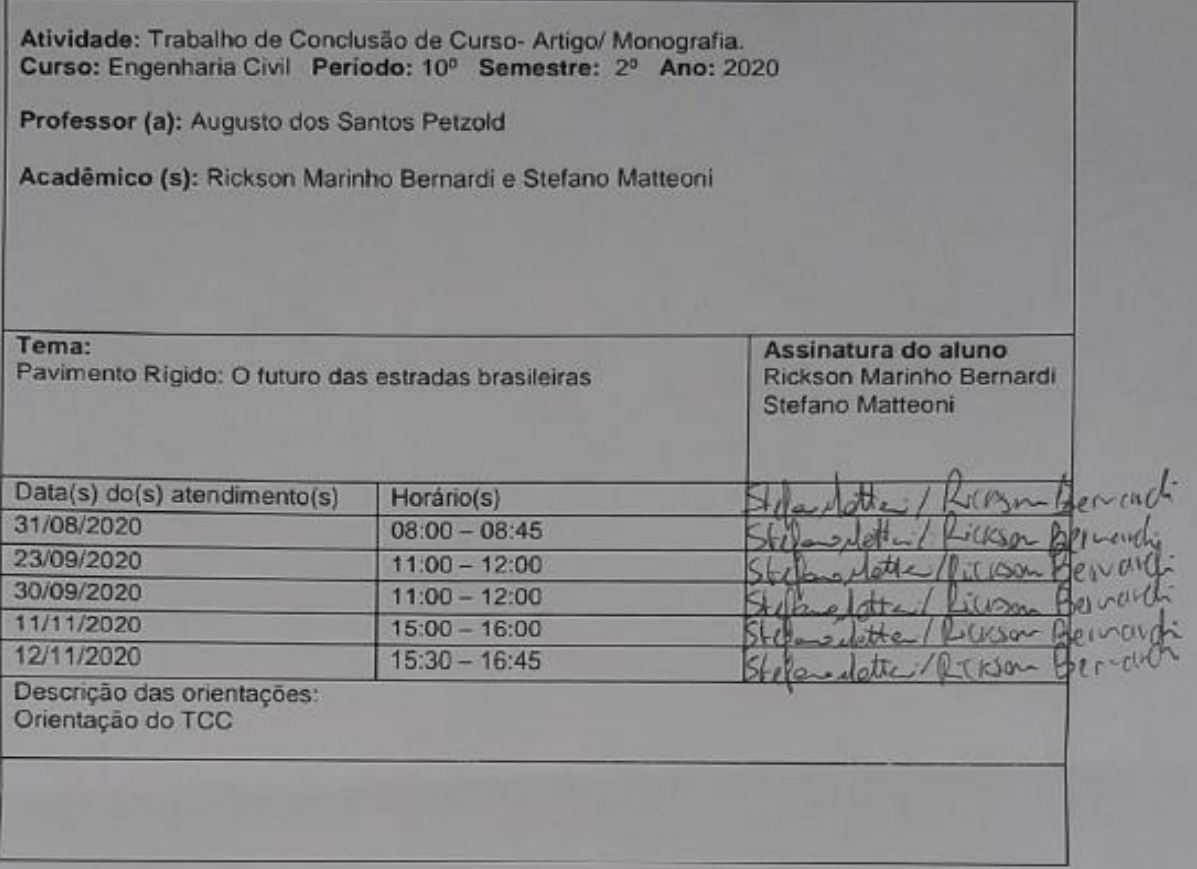

Considerando a concordância com o trabalho realizado sob minha orientaçāo, AUTORIZO o DEPOSITO do Trabalho de Conclusâo de Curso do (a) acadêmico (a) com titulo: Analise fina da pesquisa derradeira

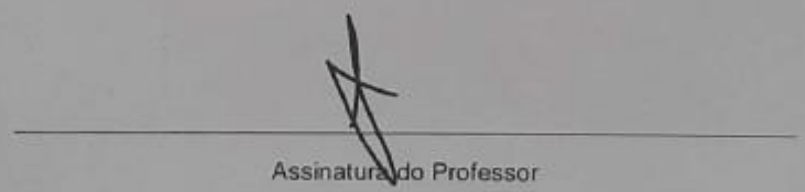


Revista Multidisciplinar do Nordeste Mineiro, v.1,

2021/01

ISSN 2178-6925

\section{RELATÓRIO DE PLÁGIO}

\section{CopySpider Scholar Apoiar o CopySpider}

\begin{tabular}{|c|c|}
\hline$\downarrow$ Exportar relatório & $\downarrow$ Exportar relatório PDF \\
\hline
\end{tabular}

TCC DEFINITIVO.docx (13/11/2020):

Documentos candidatos

mapadaobra.com.br/ca... [2,44\%]

nucleodoconhecimento... [2,08\%]

Arquivo de entrada: TCC DEFINITIVO.docx (3486 termos)

revista.ufrr.br/rct/... [1,91\%]

rdu.unicesumar.edu.b... [1,3\%]

repositorio.roca.utf... [0,93\%]

ibracon.org.br/event... [0,86\%]

monografias.brasiles... $[0,4 \%]$

britannica.com/place... [0,06\%]

britannica.com/event... [0,01\%]

youtube.com/watch?v $=\ldots[0 \%]$

$\begin{array}{lcccc}\text { Arquivo encontrado } & \begin{array}{r}\text { Total de } \\ \text { termos }\end{array} & \begin{array}{c}\text { Termos } \\ \text { comuns }\end{array} & \begin{array}{l}\text { Similaridade } \\ (\%)\end{array} \\ \text { mapadaobra.com.br/ca... } & \text { Visualizar } & 960 & 106 & 2,44 \\ \text { nucleodoconhecimento... } & \text { Visualizar } & 4844 & 170 & 2,08 \\ \text { revista.ufrr.br/rct/... } & \text { Visualizar } & 7107 & 199 & 1,91 \\ \text { rdu.unicesumar.edu.b... } & \text { Visualizar } & 318 & 49 & 1,3 \\ \text { repositorio.roca.utf... } & \text { Visualizar } & 13365 & 156 & 0,93 \\ \text { ibracon.org.br/event... } & \text { Visualizar } & 830 & 37 & 0,86 \\ \text { monografias.brasiles... } & \text { Visualizar } & 7594 & 45 & 0,4 \\ \text { britannica.com/place... } & \text { Visualizar } & 4735 & 5 & 0,06 \\ \text { britannica.com/event... } & \text { Visualizar } & 1885 & 1 & 0,01 \\ \text { youtube.com/watch?v=... } & \text { Visualizar } & 27 & 0 & 0\end{array}$

